\title{
LAS MARCAS DE DISTRIBUIDOR Y EL DERECHO DE LA COMPETENCIA EN EL ECUADOR
}

\author{
LENÍN HURTADO ANGULO ${ }^{1}$
}

\section{RESUMEN}

Las marcas representan una herramienta fundamental en el ejercicio del comercio y, consecuentemente en la competencia económica, muy recientemente en el Ecuador las marcas dejaron de ser una forma de establecer el origen empresarial y se constituyeron sólo en una forma de identificación de productos y servicios en el mercado, todo llevado por el auge de los autoservicios como forma de expendio de productos de una gran variedad. Tales canales de distribución lograron un enorme nivel de penetración en el mercado de expendio de alimentos, razón por la cual hoy es el principal mecanismo de ofrecer y adquirir tales productos. Es en ese escenario que adquieren una posición de dominio y, de acuerdo a nuestro criterio, han abusado y abusan de tal posición, en contraposición de las normas de defensa de la competencia, configurando incluso una tolerada competencia desleal.

PALABRAS CLAVE: Marca, competencia desleal, signo, daño concurrencial.

1 Abogado en libre ejercicio profesional especialista en propiedad intelectual 


\begin{abstract}
Brands represent a fundamental tool in the course of trade and, as a result in economic competition, very recently in the Ecuador brands ceased to be a form to establish the business origin and constituted only in a form of identifying products and services on the market, all led by the rise of the supermarkets as a way of dispensing products. Such channels of distribution managed a huge level of penetration in the market of retail sale of food, reason by which today is the main mechanism of offer and purchasing such products. Is in this scenery that they acquire a dominant position and, according to our criteria, they have abused of such position, in contrast to rules in defense of the competition, setting up even a tolerated competition unfair.
\end{abstract}

\title{
KEY WORDS:
}

Brand, unfair competition, sign, competitive damage. 


\section{INTRODUCCIÓN}

En la dinámica comercial actual, los autoservicio ${ }^{2}$ han adoptado como mecanismo de comercialización de los productos que expenden, hacerlo con la marca que los identifica como tales, esto es, lo que inicialmente fue un nombre comercial, se ha tornado en una marca de productos, en diferentes clases internacionales Ésta, que bien podríamos llamar novedosa estrategia de mercadeo, plantea varias interrogantes al Derecho, muy particularmente al Derecho de la Competencia, pues es innegable que los autoservicios utilizan su posición en el mercado, para ofrecer al público consumidor, productos con su identificación de marca, en condiciones de evidente ventaja frente a aquellos comercializados a través de diversos canales de distribución con un importante componente en sus costos derivados en los necesarios esfuerzos publicitarios.

Pretendemos establecer si el daño concurrencial sufrido por los competidores de los autoservicios, los que son a su vez sus proveedores, en la provisión de bienes al público consumidor es o no lícito, es una de las conclusiones a las que esperamos arribar analizando la naturaleza jurídica de tales marcas frente a los preceptos del Derecho de la Competencia y las normas pertinentes vigentes en el Ecuador.

2 El autoservicio es conocido como una forma de establecimiento en el que los productos están al alcance de las personas para que ellas mismas puedan realizar sus compras sin necesidad de asistencia. https:/ / catmanservices.wordpress.com/2010/11/02/historia-delautoservicio-en-el-mundo/ Consultado el 1 de mayo del 2016, a las $21 \mathrm{H} 24$ 


\section{LA MARCA}

Es cualquier signo que permite distinguir los productos y servicios de otros iguales o similares cuya finalidad es ser colector de clientela ${ }^{3}$.

La definición doctrinal propuesta, define la marca a partir de la función que cumple, esto es, la distinción de un producto o de un servicio, de otros iguales o similares en un mercado determinado, indicando además la vital función que desempeña en la lucha concurrencial propia de la competencia económica; de ello podemos extraer algunos elementos que son vitales en la idea que debemos hacernos sobre estos signos:

a. Aptitud del signo.- De acuerdo a definición en análisis, no todo signo puede constituirse en marca, debe cumplir con determinados requisitos para tal efecto, el Anexo 1C del Tratado de creación de la Organización Mundial del Comercio (ADPIC), señala: “... Los miembros podrán exigir como condición para el registro que los signos sean perceptibles visualmente...". En otras palabras, cualquier signo que permita su representación gráfica y con capacidad distintiva es apto para constituirse en marca y, por lo tanto, para obtener la protección legal. Será la autoridad nacional competente la encargada de establecer la idoneidad del signo para ser considerada marca, esto se hará mediante el examen de "registrabilidad", en función de las exclusiones señaladas en las disposiciones legales pertinentes. En primer lugar, se señala que el signo debe poder representarse gráficamente; "Este requisito viene impuesto por la necesidad de acomodar los nuevos tipos

3 Nava Negrete, Justo. Tratado sobre Derecho de Marcas, $2^{\text {a }}$ edición, Editorial Porrúa, México - 2012, p. 239 
de marcas surgidos en el tráfico económico a los mecanismos y las funciones de un sistema de marcas registradas"4, lo anterior se explica en el hecho de que la Autoridad Nacional competente, en el proceso de registro, cuando éste se requiera como forma de constituir derechos sobre los signos, necesita dejar constancia de la existencia del signo, realizando publicaciones para que aquellos terceros que se puedan sentir afectados por la existencia del signo, puedan ejercer su derecho a oponerse motivadamente a que se admita tal registro o que se lo cancele cuando se lo ha concedido en violación de derechos que reclame como propios el opositor.

b) La Función Distintiva del signo.- El poder o carácter distintivo de un signo, es la capacidad intrínseca que tiene para poder ser marca ${ }^{5}$ En definitiva es la posibilidad del signo de distinguir un producto o un servicio, todo en defensa de un público consumidor que, luego de haber probado el producto o de haber disfrutado del servicio, ha decidido que ese es el que cubre sus particulares expectativas, de allí que se sostiene que un signo puede tener distintividad desde un principio o adquirirla con posterioridad a su registro, lo que sí debe tener como requisito previo a su registro es capacidad distintiva. En conclusión, como consecuencia de esa necesaria capacidad distintiva que se exige de los signos a registrar como marca, no es posible la coexistencia de dos signos iguales para identificar productos o servicios iguales o similares. Este requisito está

4 Fernández Novoa, Carlos; Otero Lastres, José Manuel; BotanA Agra, Manuel. Manual de la Propiedad Industrial. Segunda Edición. Editorial Marcial Pons. Madrid - 2013, p. 505

5 OtAmend, Jorge. Derecho de Marcas, $5^{\text {a }}$ edición actualizada y ampliada. Editorial Abeledo-Perrot, Buenos Aires - 2003, pag. 27 
íntimamente ligado con la función básica de la marca; a saber: indicar el origen empresarial de los productos o servicios. En efecto, esta función tan sólo puede ser desempeñada por los signos que tienen aptitud (intrínseca o adquirida como consecuencia del uso) para diferenciar en el mercado los productos o servicios de una empresa frente a los productos o servicios de las restantes empresas. Debe señalarse que el carácter distintivo es un concepto jurídico indeterminado que tiene que concretarse caso por caso ${ }^{6}$

c. Límite territorial del derecho.- Pese a que la definición doctrinal inicialmente propuesta, no lo señala expresamente, la protección brindada por el registro marcario, tiene una limitación espacial (territorial), así lo reconocen la mayoría de las legislaciones en materia de marcas; el Art. 134 de la Decisión 486 de la CAN, señala que la distinción del producto o del servicio tendrá lugar en "un mercado determinado", tal expresión tiene una connotación territorial, es decir, cuando se obtiene un registro de un signo como marca, la protección que se logra tiene limitaciones geográficas, esto es, tal registro tendrá validez únicamente en el país registrante. Lo previamente señalado, sin perjuicio del derecho consagrado en el Art. 142 ibídem, que señala: "Cuando el solicitante deseara prevalerse del derecho previsto en el Artículo 6 del Convenio de París para la Protección de la Propiedad Industrial, deberá presentar el certificado de registro de la marca en el país de origen dentro del plazo de tres meses siguientes a la fecha de presentación de la solicitud", la disposición del Convenio de Paris aludida en la norma comunitaria, señala: "Toda marca

6 Fernández NovoA, Carlos; Otero Lastres, José Manuel; BotanA AgrA, Manuel; Ob. Cit. p. 506 
de fábrica o de comercio regularmente registrada en el país de origen será admitida para su depósito y protegida tal cual es en los demás países de la Unión, salvo las condiciones indicadas en el presente artículo. Estos países podrán, antes de proceder al registro definitivo, exigir la presentación de un certificado de registro en el país de origen, expedido por la autoridad competente. No se exigirá legalización alguna para este certificado.

Visto lo expuesto, podríamos afirmar que sería posible que dos signos coexistieran, siendo idénticos o similares, si identificaran productos o servicios en clases internacionales ${ }^{7}$ diferentes, con lo cual la posibilidad de confusión en el público consumidor sería remota, es lo que se denomina principio de especialidad. Asimismo, podrían coexistir signos iguales o similares, identificando productos o servicios en la misma clase internacional, pero en mercados diferentes, es decir, en diferentes países, con la salvedad a señalar infra en relación con las marcas notorias y las renombradas. En los derechos de propiedad industrial, por último, existe una dificultad adicional para que puede atribuirse efectividad en un país a la exclusiva otorgada por un Estado extranjero; y es el carácter estrictamente territorial del acto concesional al que se vincula tal exclusiva, que nace como un acto administrativo de un Estado concreto que, por su propia naturaleza, sólo puede tener valor y ser actuado dentro de su propio territorio. De ahí que la protección no pueda exceder esos límites territoriales y que, por tanto, la concesión

7 Clasificación internacional de productos y servicios establecida en virtud del arreglo de Niza, suscrito en dicho ciudad, el 15 de junio de 1957, revisado en Estocolmo el 14 de julio de 1967 y en Ginebra el 13 de mayo de 1977 
administrativa otorgada por un Estado no pueda tener virtualidad en los demás países ${ }^{8}$

Todo el esquema descrito se podría afirmar que constituye la regla general, en consecuencia, existen excepciones a la misma, que están dadas, en primer término, por las llamadas marcas notorias, definidas en el Art. 224 de la Decisión 486 de la CAN como: "Se entiende por signo distintivo notoriamente conocido el que fuese reconocido como tal en cualquier País Miembro por el sector pertinente, independientemente de la manera o el medio por el cual se hubiese hecho conocido"; y, en segundo término, por las llamadas marcas de alto renombre, definidas en el segundo inciso de la letra e) del Art. 196 de la Ley de Propiedad Intelectual ecuatoriana: "Se entenderá que un signo es de alto renombre cuando fuese conocido por el público en general en el país o internacionalmente".

En los casos señalados, pese a que los signos identificaran productos o servicios diferentes o se encontraran en países distintos, se excluye su registro por considerarse que, entre otras razones, se estaría aprovechando del prestigio ganado por el producto o servicios que identifica el signo notorio o de alto renombre.

Tratándose de marcas notorias, este carácter les otorga una protección incrementada que constituye excepción a la regla de la especialidad de la marca; al margen de ello, y en lo que se refiere al análisis objetivo del signo, se impone

8 Baylos Corroza, Hermenegildo. Tratado de Derecho Industrial, $3^{\text {a }}$ edición. Editorial Aranzadi, Pamplona - 2009, p. 660 
la aplicación de un criterio riguroso para admitir la inscripción o el uso de marcas que se le aproximen; de lo contrario, se aceptaría no sólo un indebido aprovechamiento del prestigio ajeno, sino que se induciría a fácil confusión, al menos en cuanto al origen de los productos, al público consumidor $^{9}$

Sobre este tipo de signos, el Tribunal Andino de Justicia ha señalado:

Este Tribunal caracteriza a la marca notoria como aquella que reúne la calidad de ser conocida por una colectividad de individuos pertenecientes a un determinado grupo de consumidores o usuarios del tipo de bienes o de servicios a los que les es aplicable, porque se encuentra ampliamente difundida entre dicho grupo.Asimismo el Tribunal ha manifestado “(...) la protección especial que se otorga a la marca notoriamente conocida se extiende -caso de haber riesgo de confusión por similitud con un signo pendiente de registro- con independencia de la clase a que pertenezca el producto de que se trate y del territorio en que haya sido registrada, pues se busca prevenir el aprovechamiento indebido de la reputación de la marca notoria, así como impedir el perjuicio que el registro del signo similar pudiera causar a

9 Bertone, Luis Eduardo - CABAnEllas de las Cuevas, Guillermo. Derecho de Marcas / 2 Marcas, Designaciones y Nombres Comerciales $2^{\text {a }}$ edición. Editorial Heliasta, Buenos Aires - 2003, p. 84 
la fuerza distintiva o a la reputación de aquélla. (Proceso 143-IP-2004, publicado en la G.O.A.C. $\mathrm{N}^{\circ}$ 1147, de 3 de diciembre de 2004, marca: BONITO+GRÁFICA).

La notoriedad de la marca no se presume, debe ser probada, por quien alega ese estatus. Al respecto el Tribunal recogiendo criterios doctrinarios, ha sentado la siguiente jurisprudencia: "En la concepción proteccionista de la marca notoria, ésta tiene esa clasificación para efectos de otorgarle otros derechos que no los tienen las marcas comunes, pero eso no significa que la notoriedad surja de la marca por sí sola, o que para su reconocimiento legal no tengan que probarse las circunstancias que precisamente han dado a la marca ese status". (Proceso 08-IP-95, publicado en la G.O.A.C. N ${ }^{\circ} 231$, de 17 de octubre 1996, marca: LISTER).

Por su parte el literal h) del artículo 136 de la Decisión 486 prohíbe el registro como marca de un signo que reproduzca, imite, traduzca, translitere o transcriba un signo notoriamente conocido cuyo titular sea un tercero, cualesquiera que sean los productos o servicios a los que se aplique el signo, es decir, por fuera de la especialidad cuando su uso pueda causar un riesgo de confusión o de asociación, aprovechamiento injusto del prestigio del signo o la dilución de su fuerza distintiva o de su valor comercial ${ }^{10}$

10 -7-X-2008 (Proceso No. 086-IP-2008, Tribunal de Justicia de la Comunidad Andina) 
Finalmente, es conveniente señalar que puede ocurrir que un signo no tenga inicialmente capacidad distintiva, pero lo adquiera con posterioridad con el uso intenso en el comercio, situación que la doctrina denomina: distintividad adquirida o "secondary meaning".

Por otra parte, si bien la inscripción en el registro, visto su efecto constitutivo, configura el único modo de adquisición de la marca y del derecho a su uso exclusivo, el signo puede alcanzar aptitud distintiva, en relación con el producto o servicio a que se refiera, como consecuencia de su uso constante y, en tal caso, hacerse registrable. Así se desprende del tenor del artículo 135, último párrafo, según el cual un signo podrá ser registrado como marca si, a pesar de no ser distintivo ab initio, o de ser descriptivo, o genérico, o común o usual, o de consistir en un color no delimitado por una forma específica, quien solicita el registro, o su causante, lo hubiese estado usando constantemente en el País Miembro y, por efecto de tal uso, el signo hubiese adquirido aptitud distintiva respecto de los productos o servicios a los cuales se aplica. En la doctrina se explica que 'un término originariamente genérico puede llegar a serlo y adquirir el carácter distintivo típico de una marca. Es el supuesto conocido en el Derecho norteamericano como de adquisición por el término genérico de un 'secondary meaning' (significado secundario) que confiere al signo el carácter distintivo propio de la marca'. (BERCOVITZ, Alberto; ob.cit., p. 471)'. (Proceso 
92-IP-2004. Caso: denominación "UNIVERSIDAD VIRTUAL”, publicado en la Gaceta Oficial $\mathrm{N}^{\circ}$ 1121, de 28 de setiembre de 2004). TRIBUNAL DE JUSTICIA DE LA COMUNIDAD ANDINA PROCESO 150-IP-2013

\section{MARCAS DE DISTRIBUIDOR}

Durante los últimos años, los precios de los productos de consumo han sufrido un fuerte incremento, al reflejarse en ellos los efectos de la política tributaria implementada en el Ecuador. Como consecuencia de este hecho, los consumidores sufren cada vez más dificultades a la hora de realizar sus compras, razón por la que buscan diferentes alternativas con el fin de reducir gastos. Una de estas alternativas consiste en la adquisición de los productos identificados con las llamadas marcas blancas o de distribuidor.

Las marcas de distribuidor son las que han sido fabricadas por un determinado industrial y son ofrecidas al consumidor bajo el nombre o marca de la empresa distribuidora y no con el de la compañía que realmente los ha elaborado ${ }^{11}$.

No cabe duda alguna que, lo que originalmente fue un nombre comercial, entendido éste como la designación de un establecimiento de negocios, se convirtió en otro tipo de signo, es decir, en una marca de producto y más aún, se convirtió en un signo notorio, pues los autoservicios que han adoptado tal alternativa de comercialización de bienes son aquéllos que

11 http://www.unae.cat/es/inici/consum/22.php?idpagina=22\&id_ tribuna $=12$. Consultado el 1 de mayo del 2016, a las $21 \mathrm{H} 07$ 
han captado un muy importante segmento en el mercado de consumidores de productos de consumo masivo.

En el Ecuador, las mayores cadenas de autoservicios, tales como: Supermaxi, Mi Comisariato, Tía, entre otras; han adoptado este mecanismo de comercialización de productos diversos en el afán de captar un mercado de personas ávidas de adquirir productos con la mejor relación posible entre calidad y precio.

Podemos afirmar que las marcas de distribuidor o marcas blancas, no son un concepto jurídico, son más bien un concepto comercial derivado de una necesidad concreta del mercado, vale decir, de la necesidad de los consumidores de adquirir productos de menor precio sin desmejorar la calidad.

Las marcas propias no son un tipo distinto de marcas, constituyen tan sólo un uso novedoso de estos signos, una manera distinta de concurrir al mercado por parte de quienes lo hacían previamente con una estrategia distinta. Si tal estrategia constituye o no abuso de posición de dominio, deberá establecerse mediante la revisión de cada caso concreto, mediante parámetros que se propondrán infra.

\section{FUNCIONES DE LA MARCA}

Una vez que se ha verificado que un signo reúne las condiciones para ser utilizado como marca, es decir, se puede representar gráficamente y tiene capacidad distintiva; puede desempeñar las funciones propias de dichos signos. Tales funciones son: indicadora del origen empresarial, indicadora de la calidad, condensadora del goodwill o buena reputación y la función publicitaria. 
De otro lado, "la ley persigue dos finalidades a la hora de regular las marcas. Una de estas finalidades está ligada a la competencia comercial que intenta promover cualquier Estado, esto es, una sana competencia comercial. La otra finalidad es la protección del consumidor, quien necesita de un sistema en el cual los competidores de bienes y servicios le permitan distinguir sin mayores inconvenientes, a través de las marcas, quiénes son los oferentes de esos bienes y servicios - para luego premiarlos o castigarlos mediante su decisión de compra o consumo". ${ }^{12}$

La función indicadora del origen empresarial, en opinión generalizada en la doctrina marcaria, es la función primordial de la marca. Cuando una persona ve un producto o se le ofrece un servicio identificado con una determinada marca, inmediatamente lo asocia a una empresa y a todos los productos o servicios que ésta comercializa.

Esta función se apoya directamente en las reacciones del público de los consumidores y se basa de modo inmediato en la propia estructura del derecho de marca. En efecto, al contemplar una marca puesta en relación con un producto o un servicio, el consumidor piensa lógicamente que el producto o servicio procede de una determinada empresa; de aquella empresa de la que proceden todos los demás productos o servicios de la misma clase que están dotados de la misma marca. En este sentido la marca desempeña un papel informativo; atestigua ante el público de

12 VIBES, Federico. Derechos de Propiedad Intelectual. $1^{\text {a }}$ edición, Ad-Doc, Buenos Aires - 2009, p. 96 
los consumidores que todos los productos de una misma clase y portadores de una misma marca han sido fabricados o distribuidos por una misma empresa $^{13}$

En lo relacionado a la función indicadora de la calidad, normalmente los consumidores por haber experimentado con un producto o servicio, por haber estado expuestos a la publicidad, que lo induce a pensar que un determinado producto o servicio es de calidad aún antes de haberlo adquirido y verificado por sí mismo o por referencias de personas que sí han consumido el producto o utilizado el servicio. Sea cual fuere el motivo por medio del cual se establezca la asociación en el consumidor del producto o servicio con un nivel de calidad, es innegable que ocurre tal proceso de relación. Algunos industrialistas, como Jorge OTAMENDI, sostienen que ésta es la verdadera función fundamental de las marcas, que la determinación del origen empresarial no es consustancial al signo ${ }^{14}$.

La buena reputación de un producto o servicio es algo que se construye con muchos elementos, tales como: la calidad de los mismos, la atención que se brinde a los potenciales clientes. Es algo que se construye con gran esfuerzo y se pierde con enorme facilidad. "La función condensadora del goodwill o buena reputación, desde la perspectiva del titular, la función más importante de la marca es la de constituir un mecanismo en el que va sedimentándose progresivamente la eventual buena reputación

13 Fernández Novoa, Carlos; Otero Lastres, José Manuel; BotanA LASTRA, Manuel. Ob. Cit. p. 507

14 Otamend, Jorge. Derecho de Marcas. $5^{\circ}$ edición, actualizada y ampliada. Editorial Abeledo - Perrot. Buenos Aires - 2003, p. 9 
(goodwill) de que gocen, entre el público de los consumidores, los productos o servicios diferenciados por la marca. Goodwill o buena fama que presupone la preferencia que el público de los consumidores otorga a los productos dotados con la marca; y entraña la expectativa razonable de que el producto será reiteradamente comprado porque cuenta con el favor del público. La función condensadora del goodwill es singularmente palpable en el supuesto de la marca renombrada que es aquel tipo de marca que se caracteriza por ser portadora de un acrecentado prestigio; prestigio que es el fruto de la alta calidad de los productos o servicios; de la intensa publicidad realizada en torno a la marca; y a veces de la fuerza sugestiva (selling power) del propio signo constitutivo de la marca"15

Finalmente, la función publicitaria es lo que permite que el producto o servicio identificado mediante la marca sea conocido por el público consumidor, no existe forma en que un producto o servicio sea conocido por sus eventuales consumidores, sino tiene un signo que permita su ofrecimiento a dicho público. De tal manera, que la función publicitaria de la marca, es la vía usada para hacer conocer las características del producto o servicio, para lograr el daño concurrencial lícito en el ejercicio del comercio, objetivo central de la competencia. Cuando un comerciante, piensa en un signo que luego registrará como marca, lo hace pensando en el potencial publicitario de tal signo, con frecuencia recurre a las marcas evocativas ${ }^{16}$ para lograr tal objetivo.

15 Fernández Novoa, Carlos; Otero Lastres, José Manuel; BotanA LASTRA, Manuel. Ob. Cit. p. 509

16 Se designan así a aquellas marcas que proporcionan al consumidor una idea de las características - o por lo menos algunas de ellas - de los productos o servicios identificados por el signo 
"La marca es el único nexo que existe entre el consumidor de producto o el servicio y su titular. Es a través de la misma que su titular recogerá los beneficios, o no, de su aceptación por parte del público consumidor. Esa marca es lo que el comprador ha de pedir y es lo que el titular de la misma tratará que pida"17

Con todo lo señalado a propósito de las funciones de las marcas, debemos indicar que las marcas de distribuidor, es decir aquellos signos incorporados a productos que no provienen de ordinario de los titulares del signo, en consecuencia, la función indicadora del origen empresarial no se cumpliría, sólo observamos el cumplimiento de las funciones de calidad y de buena reputación o goowill, dado que de ordinario los autoservicios que le dan a su denominación comercial, el uso de marcas de los bienes que expenden, han adquirido notoriedad en el mercado de consumidores de productos de primera necesidad.

\section{NACIMIENTO DE LOS DERECHOS SOBRE EL SIGNO}

Se han establecido mecanismos de obtener derechos sobre las marcas y demás signos distintivos. Las legislaciones marcarias han señalado que los derechos sobre los mismos, se adquirirán por el uso inicial y, una vez que el público consumidor haya relacionado el signo con los productos o servicios que identifica, puede procederse con su registro, a tal Principio se lo denomina Declarativo o de Prioridad por el uso. "Conforme a este principio, el derecho sobre la marca se adquiere originariamente a través de la utilización efectiva del correspondiente signo en el mercado; el derecho sobre la marca pertenece a quien la usa por primera vez para designar sus productos. Basándose en ciertos precedentes del

17 OtAmend, Jorge. Ob. Cit. p. 11 
Derecho común medieval, la doctrina francesa clásica mantenía en este punto que la propiedad de la marca corresponde al primer ocupante de la misma"18

Por otro lado, existen legislaciones - como la ecuatoriana - que disponen que el derecho sólo se adquirirá con el registro y sólo a partir de tal acto, es el Principio Registral. "Con arreglo a este principio, el nacimiento del derecho sobre la marca tiene lugar mediante la inscripción del signo en el Registro de Marcas. A través de la inscripción el titular adquiere un derecho de exclusiva sobre la marca, el cual le legitima para prohibir a los terceros el uso de signos idénticos o similares. De esta suerte, el nacimiento del derecho sobre la marca se produce mediante una inscripción registral y con independencia de que el correspondiente signo se hubiese usado anteriormente en el mercado a fin de diferenciar los productos o servicios del titular"19

\section{DURACIÓN DEL DERECHO SOBRE LA MARCA}

El Art. 152 de la Decisión 486 de la Comunidad Andina de Naciones señala: "El registro de una marca tendrá una duración de diez años contados a partir de la fecha de su concesión y podrá renovarse por períodos sucesivos de diez años". Del texto de la norma transcrita, se pueden inferir varios hechos:

a. El periodo de vigencia de la marca es, en efecto de diez años ${ }^{20}$,

18 Fernández NovoA, Carlos. Tratado sobre Derecho de Marcas. Segunda edición, Marcial Pons, Ediciones Jurídicas y Sociales S.A. Madrid 2004, p. 79

19 Ídem

20 Desde luego tal plazo podría reducirse si antes el registro caduca, se 
pero contados a partir de la fecha de la concesión de tal registro, lo cual difiere de lo otras legislaciones señalan al respecto, el Art. 31 de la Ley de Marcas de España señala que el periodo de vigencia del registro que en ese país también es de diez años y se contará a partir de la presentación de la solicitud de registro del signo: "El registro de una marca se otorga por diez años contados desde la fecha de presentación de la solicitud y podrá renovarse por períodos sucesivos de diez años";

b. El derecho de exclusividad en el uso del signo, puede extenderse de manera indefinida, si es que se ejerce el derecho de renovar el registro de manera consecutiva de la forma establecida en las disposiciones legales.

Sobre la renovación del registro del signo, la norma comunitaria señala al respecto en su Art. 153: "El titular del registro, o quien tuviere legítimo interés, deberá solicitar la renovación del registro ante la oficina nacional competente, dentro de los seis meses anteriores a la expiración del registro. No obstante, tanto el titular del registro como quien tuviere legítimo interés gozarán de un plazo de gracia de seis meses, contados a partir de la fecha de vencimiento del registro, para solicitar su renovación. A tal efecto acompañará los comprobantes de pago de las tasas establecidas, pagando conjuntamente el recargo correspondiente si así lo permiten las normas internas de los Países Miembros. Durante el plazo referido, el registro de marca mantendrá su plena vigencia. A efectos de la renovación no se exigirá prueba de uso de la marca y se renovará de manera automática, en los mismos términos del registro original. Sin embargo, el titular

declarase su nulidad y, desde luego, por renuncia realizada por su titular del signo registrado 
podrá reducir o limitar los productos o servicios indicados en el registro original". La norma en análisis establece las condiciones mediante las cuales se puede renovar el registro, podemos señalar las siguientes:

c. Puede presentar la solicitud de renovación del registro del signo, no sólo el titular del registro del signo o sus derechohabientes, sino también aquel tercero que demuestre legítimo interés en la vigencia del registro, éste podría ser el licenciatario interesado en preservar el derecho objeto del contrato de licencia;

d. Se puede presentar la solicitud de renovación del registro desde seis meses antes del cumplimiento de su periodo de vigencia, hasta seis meses después de expirado dicho periodo, en este último caso, pagando las tasas establecidas por la autoridad nacional competente en la materia;

e. A efectos de renovar el registro del signo, no se requiere justificar el uso que se esté haciendo del mismo, hecho que sí ocurría en algunas legislaciones como la Ley española de marcas de 1988, la que señala en su Art. 7.2: "La solicitud de renovación del registro de la marca deberá ir acompañada de una declaración en documento público de uso de la misma, indicando los productos o servicios en relación con los cuales la marca ha sido usada";

f. Finalmente, cumplidos los requisitos de oportunidad y aquellos formales, como el pago de las tasas correspondientes; la renovación es automática en iguales condiciones que el registro original, pudiendo el titular del registro o su derechohabiente limitar los productos o servicios que el signo identifica, tal derecho a nuestro entender, no lo puede ejercer un tercero interesado que eventualmente solicite la renovación en cuestión. 


\section{DERECHO DE LA COMPETENCIA}

Los retos que la producción en serie propuso a las economías mundiales se derivan de la enorme oferta de bienes e incluso servicios que inundaron los mercados. Importante es aclarar que esta disciplina no hizo su aparición sólo en nuestros días, en realidad las actitudes colusorias de determinados comerciantes o alguno de ellos individualmente considerados, hicieron su aparición desde los mismos orígenes de la civilización. “Así ya Aristóteles denuncia los amaños entre comerciantes en la Antigua Grecia que tendían a la elevación abusiva de los precios mediante acuerdos más o menos evidentes" 21

"El Derecho de la Competencia tiene la función de garantizar el libre mercado, como mecanismo económico mediante el cual los consumidores y las empresas fijan los precios como consecuencia del juego de la oferta y demanda de los bienes y de los servicios"22

La libre competencia se expresa como la lucha por la captación de compradores de bienes y servicios, en un escenario donde éstos son excedidos cuantitativamente por la oferta, por lo tanto, tiene lugar una disputa de ellos por parte de los oferentes que concurren al mercado a disputárselos. "La elección de los consumidores puede desarrollarse dentro de márgenes más o menos amplios, puede estar más o menos coartada por una serie de circunstancias

21 Loma Osorio Lerena, Diego. “Marco normativo e institucional del Derecho de la Competencia", en Tratado de Derecho de la Competencia, Coordinador Loma-Osorio, Diego, $1^{\circ}$ edición, Aranzadi, Pamplona - 2013, p. 40

22 ibídem, p. 34 
diversas -el lugar de residencia, la urgencia de la necesidad a satisfacer, la influencia de la propaganda, y tantas otras más-; pero ha de existir para que podamos decir que se da el fenómeno de la competencia"23

En aquella disputa concurrencial se ve reflejada el ejercicio del derecho de los oferentes de bienes y servicios a la libertad de competir; pero ésta debe encuadrarse en los parámetros propios de la competencia, esto es, la libre fijación de los precios con base en la oferta y la demanda; la libertad de elección de los compradores; y, que las empresas que concurren, no basen en su sola voluntad sus políticas industriales, comerciales y de ventas, que éstas se basen en la interdependencia de los diferentes actores económicos.

Es esencial para la existencia de la competencia que los precios sean invariablemente producto de la relación oferta - demanda, ningún competidor debe tener la posibilidad de evadir de manera absoluta tal principio en la fijación de los precios, de lo contrario habría adquirido un poder tal que haría inexistente la competencia misma.

En lo relacionado a la libre elección de los compradores, debemos señalar que esta condición de existencia de la competencia en un mercado determinado, se podría decir que es relativa, debido a que, en la lucha por distinguirse en el mercado, un oferente de un producto o un servicio adopta una determinada política

23 Fernández López, Juan Manuel. “La Competencia como fenómeno económico y como situación de mercado", en Tratado de Derecho Industrial, Baylos Corroza, Hermenegildo, $3^{\mathrm{a}}$ edición, Coordinado por Baylos Morales, María, Aranzadi, Pamplona - 2009, p. 301 
de publicidad o de mercadeo que produce en los compradores una identificación con él, que lo mueve a aceptar su oferta; si tal resultado, es producto de su creatividad y esfuerzo empresarial, el daño concurrencial que le produce a sus competidores, sería absolutamente lícito.

Finalmente, ningún competidor, puede abstraerse de la actuación de los demás en la fijación de sus políticas industriales o de ventas, éstas deben estar basadas en la situación del mercado y a las actuaciones de los demás actores, deben ser una respuesta a ellas.

Es importante destacar que el Derecho de la Competencia, tiene dos aspectos fundamentales, podríamos decir que el primero tiene por finalidad el establecer los mecanismos idóneos en los que se deberá proponer la lucha concurrencial, esto es, el Derecho de Defensa de la Competencia, al que se le atribuye, podríamos concluir, una labor promotora de la pulcritud en la lucha concurrencial en beneficio del mercado; mientras que en segundo lugar aparecen las normas de la Competencia Desleal, las que están llamadas a sancionar las conductas socialmente reprochables en el ejercicio de la competencia.

mientras que la defensa de la competencia lucha contra aquellos fenómenos que intentar limitar la competencia y poner en peligro el interés económico en general, a través de la protección contra la competencia desleal se pone el acento sobre el amparo de los intereses privados del competidor contra los actos de su propio competidor, reprochando aquellas prácticas desleales que logran que los consumidores se 
vean atraídos no por el mejor empresario, sino por aquel que utilizó medios que escapan a los parámetros socialmente aceptados ${ }^{24}$

\section{LICITUD DEL DAÑO CONCURRENCIAL}

Como se ha mencionado supra, quienes ejercen actos de comercio, vale decir, quienes en la provisión de bienes y servicios en un mercado determinado concurren a él, pugnan por lograr la preferencia de los consumidores hacia los que ofertan, cada ocasión en que tienen éxito, es un fracaso para sus competidores, es el denominado daño concurrencial, lo que es perfectamente legítimo, si para lograrlo se ha empleado mecanismos empresarial y socialmente válidos, caso contrario se adecuaría a lo que en Derecho de la Competencia se denomina: Competencia Desleal.

"La actividad concurrencial se manifiesta, pues, como un esfuerzo dirigido a conseguir ventas actuales y a asegurarse adhesiones para el futuro, de modo que en torno a cada empresa se forme un núcleo de compradores eventuales que se denomina clientela" 25

Es de destacar que la competencia tiene implícitos al mismo tiempo, valores individuales como sociales. Individuales, pues todo comerciante oferente de bienes o servicios, persigue el objetivo de aumentar su patrimonio mediante su actividad, pero sólo lo ha de lograr al cumplir el objetivo social de satisfacer a

24 García MenÉndeZ, Sebastián Alfredo. Competencia Desleal. Actos de desorganización del competidor. $1^{\text {a }}$ edición, Lexis Nexis, Buenos Aires - 2004, p. 22

25

ídem, p. 304 
los compradores en la provisión de los bienes o servicios que requiere.

Es evidente que al empresario le moverá el objetivo de obtener la mayor ganancia posible, es decir, un estímulo egoísta. Pero para conseguirlo, ha de tener compradores, han de lograr captarse las preferencias del consumidor, a cuya elección quedará sometido. Quien logre ese favor, habrá conseguido su objetivo egoísta, pero ello querrá decir que ha acertado a satisfacer las exigencias de los consumidores, es decir, las necesidades sociales (...). De aquí se desprende que es consustancial con un régimen económico de esta clase la existencia del riesgo empresarial, de esa posibilidad de enriquecimiento o de ruina, dependiente de modo fundamental del juicio y de la elección de los consumidores. Si el éxito o el fracaso, en lugar de depender de haber sabido o no lograr tales preferencias, puede atribuirse a otros factores extraños, el sistema económico se resentirá en sus propios fundamentos y el sometimiento de la producción a un fin social propio habrá de ser encomendado a otros resortes $^{26}$

\section{POSICIÓN DE DOMINIO}

Es evidente que los factores de la competencia señalados se mueven entre lo que bien podríamos llamar un franja de tolerancia

26 ídem, p. 311 
en donde en un extremo se encuentra el ideal cumplimiento de todos ellos, lo que podríamos llamar Competencia perfecta $y$, en el otro, el Monopolio. Lo que ocurre de corriente, es que el mercado posibilita observar, por parte de los concurrentes, conductas intermedias, es decir, se cumplen en la medida de lo posible, permitiendo que logren, basados en su habilidad y creatividad empresariales, posiciones de dominio donde pueden consolidar en su beneficio un segmento del mercado, en una suerte de monopolio condicionado, es decir, se origina la Competencia Imperfecta, donde los precios no se fijan solamente en la interacción entre la oferta y la demanda, sino que bien pueden intervenir otros factores, tales como, la eficiencia en el uso de los recursos que permita una elevada productividad, uso de tecnologías que derivan en la disminución de los costos, etc. ${ }^{27}$

Asimismo se admite canalizar, con técnicas publicitarias, la voluntad de los consumidores de manera que adquieran los productos o servicios de un oferente en lugar de los de otros; $y$, desde luego, puede ocurrir que ocasionalmente, los competidores puedan incidir en el mercado, de manera que, sus políticas industriales o de ventas, sí sean derivadas de su posición de dominio, sin que éstas prácticas puedan ser consideradas abusivas.

De todo lo anterior, se puede inferir que el problema no es disfrutar de una posición de dominio en el mercado, en tanto ésta sea producto de usar las reglas de juego empresarialmente aceptables y que tal posición no se ejerza abusivamente en el mercado en contra de la competencia. 
La Ley Orgánica de Regulación y Control del Poder del Mercado $(\text { LORCPM })^{28}$, en su Art. 7, define lo que se debe entender como Posición de Dominio: "Tienen poder de mercado u ostentan posición de dominio los operadores económicos que, por cualquier medio, sean capaces de actuar de modo independiente con prescindencia de sus competidores, compradores, clientes, proveedores, consumidores, usuarios, distribuidores u otros sujetos que participen en el mercado"

La norma antes referida, reitera que no es la existencia de la posición de dominio la que atenta contra a la competencia, señala expresamente que es su abuso lo que trasgrede sus preceptos: "La obtención o el reforzamiento del poder de mercado no atentan contra la competencia, la eficiencia económica o el bienestar general. Sin embargo, el obtener o reforzar el poder de mercado, de manera que impida, restrinja, falsee o distorsione la competencia, atente contra la eficiencia económica o el bienestar general o los derechos de los consumidores o usuarios, constituirá una conducta sujeta a control, regulación y, de ser el caso, a las sanciones establecidas en esta Ley"

En el Ecuador, no cabe duda, por la extendida aceptación entre los consumidores del mecanismo de compra de bienes diversos que constituyen en la actualidad las compras en los autoservicios, éstos ejercen una posición de dominio en los términos definidos por la Ley. Lo que se debe determinar es si el uso de sus marcas, puede adecuarse a lo que también normativamente se tipifica como abuso de tal posición (Art. 9 LORCPM)

28 Publicada en el Suplemento del Registro Oficial \# 555 del 13 de octubre del 2011 
Cuando los autoservicios utilizan marcas propias para la comercialización de productos de la más variada naturaleza, lo hacen prevalidos de una posición de privilegio que han alcanzado luego de que el mecanismo de expendio de tales productos, ha sido adoptado masivamente por la población. Son muy pocas las personas que no han experimentado el comprar en un autoservicio.

Desde el 2011 luego de la aprobación de la Ley Orgánica de Regulación y Control del Poder del Mercado, se creó la Superintendenciade Control del Poder del Mercado, este organismo se encontró con una situación que bien podría considerarse como una distorsión del mercado: los productores y proveedores de los autoservicios estaban perdiendo su participación en el mercado, como consecuencia de que el canal de distribución que habían considerado como el óptimo, estaban siendo usados en su contra, a tal extremo que el naciente organismo de control del poder del mercado, tuvo que emitir una resolución para enfrentar tal situación. El 29 de agosto del 2014, se dictó la Resolución \# SCPM-DS-057-2014, que contiene el Manual de Buenas Prácticas Comerciales para el Sector de los Supermercados y/o Similares y sus Proveedores; mediante la cual se pretende normar las relaciones entre los autoservicios y sus proveedores.

Los autoservicios en el normal desarrollo de su actividad comercial, acumulan una gran cantidad de información relacionada a la rotación de los productos que expenden. Tal información es usada comúnmente para establecer qué productos se identificarán con su marca (marca propia), aún más, posee información sobre qué presentación de tales productos tienen mayor rotación (venta). 
De forma similar pueden establecer una especie de política de manejo de inventarios, pues conocen los productos que se venden en mayor volumen y las épocas en que los consumidores los buscan con más frecuencia. Podemos decir sin sombra de duda, que los autoservicios llegan a un mercado ya abierto por los productores de bienes que se han ganado la confianza de los consumidores y se aprovechan del novedoso servicio que brindaban y en el camino introducir, en tales condiciones, los productos adquiridos a los fabricantes y venderlos con su marca, con una inversión significativamente menor.

De lo anterior podemos afirmar que los autoservicios establecen sus políticas de venta sin que para ello incidan los demás actores económicos $\mathrm{y}$, con ello, los precios de venta de los productos identificados con sus marcas, tienden a ser de menor precio que aquellos de la competencia.

\section{CONCLUSIONES}

Las marcas de distribuidor o blancas, cumplen con todos los requisitos exigidos a este tipo de signos pese a que inicialmente se limitaban a distinguir locales comerciales, es decir, eran nombres comerciales en el sentido jurídico del término que posteriormente se emplearon para distinguir productos.

Es incuestionable que los autoservicios acumulan una gran cantidad de información sobre el comportamiento del mercado, vale decir, sus principales hábitos en la adquisición de productos de toda naturaleza y esa información es usada en la fijación de sus políticas de ventas, lo cual trasgrede seriamente uno de los principales preceptos del Derecho de Defensa de la Competencia (Vid supra 3), es decir, que dicha política debe ser producto de la interrelación entre los agentes económicos. 
También ha quedado claro que los autoservicios, de ordinario, gozan de una posición de dominio en el mercado, la cual es utilizada en detrimento de la competencia, esto es, sus propios proveedores o los fabricantes de los productos que expenden con sus marcas. Todo lo anterior pese a los intentos regulatorios contenidos en las normas del Manual de Buenas Prácticas Comerciales para el Sector de los Supermercados y/o Similares y sus Proveedores, aprobado por la Superintendencia de Control del Poder del Mercado, así definido en el Art. 9.7 de la LORCPM

Dado lo difícil de la regulación de las prácticas identificadas como de abuso de posición de dominio por parte de los autoservicios, toda esta situación es tolerada por el mercado y desde luego por las autoridades llamadas a impedir que se materialicen, pues finalmente el consumidor, razón primigenia de las normas sobre el derecho de la competencia, es el beneficiado al adquirir productos de calidad a precios muchos menores que los de los productos identificados con las marcas de los productores.

La afirmación anterior no puede ser óbice para enfrentar el problema en ciernes, puesto que puede, sin problema alguno, derivar en la formación de un oligopolio de autoservicios, lo que derivaría en la total destrucción de la competencia, escenario que sí implicaría una afectación al consumidor al eliminar su derecho a escoger con libertad los productos que desea consumir. 


\section{BIBLIOGRAFÍA}

BAYLOS Corroza, Hermenegildo. Tratado de Derecho Industrial, $3^{\text {a }}$ edición. Editorial Aranzadi, Pamplona - 2009

BERTONE, Luis Eduardo - Cabanellas de Las Cuevas, Guillermo. Derecho de Marcas / 2 Marcas, Designaciones y Nombres Comerciales $2^{\text {a }}$ edición. Editorial Heliasta, Buenos Aires $-2003$

FERNÁNDEZ LÓPEZ, Juan Manuel. "La Competencia como fenómeno económico y como situación de mercado", en Tratado de Derecho Industrial, Baylos Corroza, Hermenegildo, $3^{\text {a }}$ edición, Coordinado por Baylos Morales, María; Aranzadi, Pamplona - 2009

FERnÁNDEZ-NOVOA, Carlos; Otero Lastres, José Manuel; Botana Agra, Manuel. Manual de la Propiedad Industrial. Segunda Edición. Editorial Marcial Pons. Madrid 2013

, Tratado sobre Derecho de Marcas. Segunda edición, Marcial Pons, Ediciones Jurídicas y Sociales S.A. Madrid $-2004$

GARCÍA MENÉNDEZ, Sebastián Alfredo. Competencia Desleal. Actos de desorganización del competidor. $1^{\mathrm{a}}$ edición, Lexis Nexis, Buenos Aires - 2004 
LOMA-OSORIO LERENA, Diego. "Marco normativo e institucional del Derecho de la Competencia”, en Tratado de Derecho de la Competencia, Coordinador LomaOsorio, Diego, $1^{\circ}$ edición, Aranzadi, Pamplona - 2013

NAVA NEGRETE, Justo. Tratado sobre Derecho de Marcas, $2^{\text {a }}$ edición, Editorial Porrúa, México - 2012

OTAMENDI, Jorge. Derecho de Marcas, $5^{\text {a }}$ edición actualizada y ampliada. Editorial Abeledo-Perrot, Buenos Aires 2003

VIBES, Federico. Derechos de Propiedad Intelectual. $1^{\text {a }}$ edición, Ad-Doc, Buenos Aires - 2009

http://www.unae.cat/es/inici/consum/22.php?id_pagina=22\&id_ tribuna $=12$. 